\title{
Learning from childhood: children tell us who they are through online dialogical interaction
}

DOI 10.1515/ijtr-2016-0001

received February 2016; accepted April 2016

\begin{abstract}
Philosophy of childhood is a field of inquiry in which the protagonists are adults, who are trying to understand children, and children, who are trying to be understood by adults. These two operating agents must find a common ground that renders their communication possible. This piece develops and illustrates the notion that no theorisation can exist if the authors of the theories do not know the subjects of their study, and thus that philosophers of childhood cannot contribute to knowledge about childhood unless they create occasions for the voices of children to be heard. Therefore, when activities are devised for the free expression of childhood, they cannot meaningfully be categorised as separate from philosophy of childhood. The latter cannot exist without the former. Philosophy of childhood and philosophy for children are interlaced in their work with children. Once the nature of childhood is understood through what children tell about themselves, instead of narrated through the interpretive frameworks of adults, the rights of the children can be effectively protected.
\end{abstract}

Keywords: Philosophy of childhood; Collaborative learning; Child protection

\section{Introduction}

Philosophy of childhood is a reflection on children. This reflection has the scope to know childhood better in order to protect it more appropriately. The defense of the rights of children requires knowledge of childhood based on its free expression. Childhood must have the

*Corresponding author: Susanna Saracco, Viale Nuvoli 60, 10098

Rivoli (TO), Italy E-mail: ssar4806@uni.sydney.edu.au possibility to let adulthood know what being a child means without being forced to convey this message through the mentality of the adults. Nonetheless, children and adults need to have a common ground that renders their communication possible. The creation of this common ground calls for the participation, in the analysis of childhood, of philosophy for children.

The intervention of philosophy for children must become accustomed to the recognition that contemporary society is not only characterised by unpredictability but also by speed. In the twenty-first century we have not only to adapt to variations but also to cope with the rhythm of these changes. To be able to face adequately the challenges that present themselves in contemporary society we need to learn to rely on others: communication and cooperation are crucial (Brown and Lauder 2000, 1766-1777) when we have to take into consideration the diverse facets of complex scenarios. For this reason, I have devised a learning environment in which students realise that the responsibility of facing a challenging scenario benefits from multiple contributions. This realisation will in turn support the recognition of the value of the reflections and reasoning processes of every member of the team.

Elementary students will engage in structured collaborations to solve complex philosophical problems. Supported by tailor-made software, students who attend schools in upper-class communities will participate in intensive dialogues online with students who attend schools in less privileged communities. They will discuss scenarios in which they are guided by questions that encourage them to explore the distinction between fact and opinion. These scenarios will comprise examples connected to the students' everyday life experiences. The challenges presented by the learning units will give students the chance to see the value of drawing on different points of view to make complex decisions. The collaborative environment will be strengthened by the teachers' encouragement of expression without their advocacy of one particular line of reasoning. The relevance of the scenarios to the lives of the students will support the transfer to their everyday lives of both the 
outcomes and processes of critical, collaborative evaluation they have developed.

\section{Philosophy of childhood and phi- losophy for children}

Philosophy of childhood (Kennedy 2006, 16) involves two agents: adults, who interrogate themselves about the possibility of knowing childhood, and children, who must have the possibility of being known by adults. You cannot theorise about a subject if you have no chance to know that subject. The easiest way to know the subjects of your research is to give them the chance to express themselves. Philosophy of childhood has 'childhood' as its subject of interest. Thus, it is important that its theorisation starts from the knowledge of childhood. Children cannot be known if they have no possibility to show who they are: it is necessary to design activities for children so that they provide us with the matter for our theorisation of childhood. For this reason, when there are activities created to offer children the possibility that their voices are heard, these should not be simply categorised as philosophy for children, disconnected from philosophy of childhood. Both the subjects converge in philosophy with children. Without the interaction adulthood-childhood we do not know anything about childhood and, consequently, we cannot theorise about childhood in a way that renders justice to its complexity, creating the premises for an adequate defense of it.

This interdependence of Philosophy of Childhood and Philosophy for Children is well documented in The Ring of Gyges, written by Gareth Matthews (Matthews 2000, 3-11). There Matthews used classic philosophical texts to stimulate the critical skills of elementary school children. In particular, he read the passage of the Republic about the ring of Gyges (Matthews 2000, 4) and he started a conversation with the children about the possibilities created by a ring that can render us invisible, asking them: "well, what do you say...if you had the ring of Gyges, would you steal whatever you wanted?"(Matthews 2000, 5) Matthews reported the reply of a girl, whom he chooses to call "Anna:" (Matthews 2000, 5)

Sure, most of us would do some bad things...things we wouldn't have done otherwise; but then, with a magic ring like that, some of us would also do some good things we might not otherwise do....It could be fun to do something nice for someone who wouldn't be able to find out who had done the good deed. (Matthews 2000, 5)

As Matthews observed, Anna's comment questioned very effectively the assumption that human beings are motivated exclusively by egoistic desires (Matthews 2000, 5-6). Matthews emphasised that such a deep reflection on human motivation had not been elaborated by any of the many university students with whom he had discussed the Ring of Gyges (Matthews 2000, 6). A boy, named by Matthews "Adam,"(Matthews $2000,6)$ was puzzled about the functioning of the ring. He wondered whether the ring made invisible only the person who wore it. In this case, if this person chose to steal a TV set while she was invisible, the TV set would remain visible and a floating TV set would certainly look suspicious (Matthews 2000, 6). Adam's observation stimulated a reflection on the practical consequences of possessing a ring that renders invisible. This reflection highlighted possible weaknesses of Plato's thought experiment, which were not apparent before having taken into consideration its details (Matthews 2000, 6).

The first methodology that Matthews used to do philosophy with children consisted of the discussion of a classic text in philosophy, which could be understood by young students. Matthews provided guidance to the children, making the conversation start with an interesting question, but then he left the students free to develop their arguments. He elaborated activities for children that opened up the opportunity for their ideas to emerge. These ideas, such as Anna's and Adam's thoughts on invisibility, have been commented by Matthews, emphasising their originality and intellectual depth. This is Philosophy of Childhood. It is philosophy that has as its subject childhood. Of course, no reflection can be elaborated on an unknown subject. For the subject of childhood to be knowledgeable we need activities studied for the expression of childhood.

The second method used by Matthews to do philosophy with children consisted of the elaboration of a story, inspired by an excerpt of the Republic about the parts of the soul, that was discussed with the children (Matthews 2000, 6-10). Matthews, to discuss the partition of the self, invented an analogy of a person sitting still on the moving bus to replace the analogy used by Plato. Plato used the image of a perfectly spinning top to illustrate the idea that something can both move and be at rest at the same time. In fact, if we could see a top spinning perfectly in place, we could state that it is "moving with respect to its outer surface, but it would 
be at rest with respect to its axis."(Matthews 2000, 8) Matthews thought that the spinning top was an analogy too complex to be grasped by the children. However, in the discussion that took place in class, they revealed a quite sophisticated reflective capacity, emphasising that a human being can never be completely at rest because, even when she is sitting, her heart has to beat if she is alive (Matthews 2000, 8). Moreover, the children found Plato's idea that "every self has different parts...immediately plausible, even natural:”(Matthews $2000,8)$ Alex identified the parts as reason and appetite, in perfect correspondence with the Platonic definition of them. The demonstration that Alex was not merely reporting notions that he previously heard came from his capacity of elaborating his own special terminology to distinguish reason from appetite: "There is a wiser one....and a wanting one; the wanting one wants something and the wiser one says 'No."'(Matthews 2000, 8)

Furthermore, the students stressed that the competing desires could be more than two and that a conflict could take place between two good desires or two bad ones. This latter idea is a very good criticism of a traditional way of seeing a contrast between desires as a mere fight of reason with appetite (Matthews 2000, 9). Another good observation made by the students is that there are different messages coming to the brain, and the brain has to select the message that will inform a decision. This last reflection helped Matthews to realise that the students had dealt with a problem that he considered crucial in the discussion about the parts of the self, the problem of responsibility. In fact, one of the students, following the discussion about the different inputs received by our brain, emphasised that "You don't do anything unless the mind agrees to it."(Matthews 2000, 10) This comment demonstrated that it is clear to the student that there is me beyond any kind of part (Matthews 2000, 10).

Matthews ended his research stressing the importance of letting children free to express themselves:

the virtue of patience in doing philosophy with children is crucial. Again and again I find that, if one can only wait expectantly a little longer, somebody will come up with the question or comment or bit of reasoning that will break the logjam and produce a much more interesting discussion than would have resulted if one had fallen back to the lecture mode that seems so natural to us college teachers. (Matthews 2000, 11; my emphasis)

The second method that Matthews utilised to do philosophy with children was based upon the invention of a story, focused on an excerpt from a text of classic philosophy. This story was the starting point for the philosophical reflection of the students. Again, as with the first method employed by Matthews, in the second method, the philosophy of childhood and philosophy for children were interlaced: Matthews elaborated educational material for children, giving them the chance to demonstrate their ability as thinkers. The results of the application of philosophy for children grounded the existence and progress of philosophy of childhood.

The expression of the intellectual ability of the children gives adults the chance to sharpen their considerations of childhood. In the next section of this article, I will briefly outline a project that I have elaborated: it is based on learning units in which Plato's philosophy is utilised as an occasion to stimulate the critical skills of students attending schools in under-resourced and more privileged communities. This project will give us the chance to reflect on the transformative potential of the children's minds: childhood that expresses itself freely is able to make adults realise that their idea of childhood could be based on prejudice rather than on objective judgement.

As I said, the units that constitute the project are centred on Plato's philosophy. I am aware of the fact that the choice of Plato's thinking can be controversial. The explanation of the reasons why the attribution to Plato of an elitist mentality does not reflect the thought that he expresses in his work exceeds the scopes of this article. Nonetheless, it is important to notice this Platonic statement:

\begin{abstract}
education is not what some people declare it to be, namely putting knowledge into souls that lack it, like putting sight into blind eyes...the power to learn is present in everyone's soul...education...isn't the craft of putting sight into the soul. Education takes for granted that sight is there but that it isn't turned the right way or looking where it ought to look, and it tries to redirect it appropriately. (Republic, VII 518 b-d; my emphasis)
\end{abstract}

In this excerpt Plato mentions the soul. The Platonic notion is very different from our contemporary idea of the soul. The analysis of this topic is not necessary to grasp Plato's message; for its understanding is sufficient that we reason in terms of self instead of soul, as Matthews did (Matthews 2000, 8).What Plato is saying is that everyone is capable of learning because everyone's self possesses this power. The power to learn for Plato is the power given to every human being by her rational faculty. Reason is the turning point in the process of learning. Thus educators have to make sure that the stu- 
dents are looking in the right direction, the direction of the truth that results from the proper exercise of the reasoning skills of the individuals.

\section{Children and adults change each other}

As indicated above, it is crucial to consider philosophy of childhood and philosophy for children as complementary, both grounded in a philosophy with children that is indispensable to create the necessary space for the free expression of childhood. This possibility grounds the premise to see childhood not anymore as mere passage into adulthood but as a phase of life possessing value in itself.

The work of Matthews that we have analysed was published in 2000. That same year, Brown and Lauder published their theories about collective intelligence (Brown and Lauder 2000, 1753-1779). For them, social advancement in the twenty-first century, calls for the extension of the concept of intelligence: intelligence is not only logical or mathematical but also emotional and personal (Brown and Lauder 2000, 1766). In particular, emotional and personal intelligence are crucial in contemporary society, "a society characterised by risk and insecurity," (Brown and Lauder 2000, 1766; my emphasis) that demands "the ability to apply new skills and techniques, to emphatise and to have the personal skills needed to communicate and live alongside others" (Brown and Lauder 2000, 1766; my emphasis): a new collective consciousness, a "collective intelligence" (Brown and Lauder 2000, 1767; my emphasis) in which the others are seen as allies rather than enemies (Brown and Lauder 2000, 1767; my emphasis) is fundamental to solve effectively the complex problems that contemporary society presents. The development of collective intelligence is stimulated by the development of the "art of conversation,"(Brown and Lauder 2000, 1770) that allows collective intelligence to express itself, giving voice to all members of society (Brown and Lauder 2000, 1770).

Matthews, like Brown and Lauder, emphasised the necessity to learn from the thinking of others, as it was done by the children who were discussing philosophy in his classrooms. This exposition to different points of view is crucial to develop the capacity to adapt rapidly to the diverse challenges of the twenty-first century. Adaptation is natural in the child, as protagonist of the process of growth (Kennedy 2006, 43): the child "represents the emergent, the interruption of established forms, the possibility of bringing something new into a human world....on the verge of transformation.”(Kennedy 2013, 152). In a century where unpredictable changes take place at a very fast speed, the talent of the children to consider a situation using a novel perspective has not to be merely appreciated. Its cultivation has to be a primary goal.

I am going to outline a project that I have elaborated for students from 8 through 12 years of age. The project gives children the possibility to tell adults who they are, without being forced to express what adults think that children are or should be: new perspectives of analysis of the reality of being a child in contemporary society can emerge and, with them, new strategies for the protection of the rights of children can be developed.

At the core of the project, there is the respect of the reasoning capacities of the children, the encouragement of their creative originality and the nourishment of diversity as a resource. The project is based on learning units, that I have created. The students will work on the units online. They will be able to write brief comments: ${ }^{1}$ in the online discussions, such as those of the units shown below, the annotations will appear in the adjacent margin. Participants of the dialogue will be not only the students of a single classroom but also students that they will meet for the first time working online on the units; in this way, students who attend schools in under-resourced and more privileged communities will live the importance of collective intelligence, realising that extraordinary challenges require collaboration to be overcome.

The units of the project, as the one quoted below, revolve around a learning pattern, Plato-example taken from the everyday life of the children-followed by questions, that has been devised to develop the critical ability of the children: the students will live the fact that, regardless of their backgrounds, they can be active members of their community as thinking beings. They will transfer their critical competence in the analysis of the issues pertinent to the community in which they live. The critical capability that these children will have acquired will contribute to the well-being of society. As the following unit shows, the students are invited to reflect critically on a scenario, starting from a situation which can be experienced by them in their

1 A detailed description of the technological ensemble necessary to implement the project is not the subject of this work and is available from the author. 
everyday life: in this case, the possibility that the restitution of an item, such as a weapon, is not always the best choice to make. This critical evaluation is not individual but it relies on an online collaboration that helps students unveil different facets of the problem.

The results of these reflections are the subject of analysis of philosophy of childhood and they exist because of an online learning environment created for children: adults have created occasions for the free expression of childhood and children, via this method, not only sharpen their critical skills but also offer adults the possibility to realise what their minds can do. Consequently, adults can protect the rights of the children, grounding their fight for children not on their opinion of what childhood is but on what childhood has showed about itself.

\section{OBJECTION TO THE FIRST DEFINITION OF JUSTICE}

If a sane man lends weapons to a friend and then asks for them back when he is out of his mind, the friend should not return them.

Here Plato wants us to understand that giving back what one has received is not always the best decision to take. Do you agree or disagree? Think about this situation: your best friend steals the wallet of his older brother to buy a videogame. You find the wallet and you realise what is happening: should you give the wallet back to your friend so that he is free to waste his brother's money or would be better for your friend if you give the wallet back to his older brother?

In the units of the project, as the one quoted above, the learning path is characterised by the same elements, outlined in the first part of this article, used by Matthews to do philosophy with children: there are quotations taken from Plato's text, as in the first methodology used by Matthews; moreover, the examples related to the everyday life of the students, can be associated with the second methodology employed by Matthews, in which stories were invented to clarify the meaning of a philosophical passage. Nevertheless, these learning devices in Matthews were not part of a unitary effort that aims at stimulating the critical capacities of the students, giving them also the chance to realise the utility of these skills in relation to the solution of problems of their everyday life.

At the core of my project lies the respect of the right of the students to display their rational potential in its full extent. This project offers a learning environment in which the students are stimulated to be creators of knowledge. Children have not to absorb passively notions shaped by the minds of the adults but they are invited to criticise them, sharpening in this way their rational talent. The students involved in the project do not have to reproduce the learning modalities offered via the units; they will not have to report the point of view of their teachers as the right one; they will not have to accept one particular solution to a problem to obtain a good grade. ${ }^{2}$ The students are invited to mould the content and the method of the learning path, in an effort which is at the same time cognitive and metacognitive.

The activities of the project point to the right of the students to become themselves, developing their rational potential as critical thinkers; moreover, the students will be exposed to the importance of responsibility, mentioned by Matthews analysing the parts of the self. If you participate in the online conversation, and you do not respect the right of the others to be themselves, you will be exposed to the criticism of the whole community. Thus, even if the project guarantees the free expression of the thoughts of the students, they will be responsible for the boundaries created by their lack of respect of the others.

The weekly activities, online and in class, are designed to let the children free to express themselves as rational beings. This is not a project in which the students can only accept the content offered by the teachers as the right solution. In this project the content is created by the students through a dialogical interaction in which students and teachers learn from each other (Freire 1970, 80-81). The formation of children who are aware of their potential as thinkers requires that the adults accept the wonders that their minds will create: adults have to be ready to be surprised by children. Matthews, while he was doing philosophy with children, was happy to be surprised by the talent of his students. The full development of the capacities of the students as critical thinkers calls for the will of the adults to be questioned. In the project that I have elaborated both the teachers and the researchers have to be ready to accept this challenge, since the students will be stimulated to criticise not only the content of the units but also the dialogical method at the base of the project, as this learning unit shows:

2 On these aspects of the project see also Saracco, S. (2016). Difference as a Resource for Thinking: An Online Dialogue Showing the Role Played by Difference in Problem Solving and Decision Making. Metaphilosophy. 47 (3): 467-476 


\section{THRASYMACHUS: CRITICISING THE METHOD}

The first Book of Plato's Republic ends with Thrasymachus' intervention. Plato portrays him as a very impatient person...

While we were speaking, Thrasymachus had tried many times to take over the discussion but was restrained by those sitting near him, who wanted to hear our argument to the end. When we paused after what l'd just said, however, he couldn't keep quiet any longer. He coiled himself up like a wild beast about to spring, and he hurled himself at us as if to tear us to pieces.

Polemarchus and I were frightened and flustered and he roared into our midst: What nonsense have you been talking, Socrates? Why do you act like idiots by giving way to one another? If you truly want to know what justice is, DON'T JUST ASK QUESTIONS AND THEN REFUTE THE ANSWERS simply to satisfy your competitiveness or love of honor. You know very well that it is EASIER TO ASK QUESTIONS THAN ANSWER THEM. GIVE AN ANSWER YOURSELF, and tell us what you say the just is. And don't tell me that it's the right, the beneficial, the profitable, the gainful, or the advantageous, but tell me clearly and exactly what you mean; for I won't accept such nonsense from you.

Here Thrasymachus is criticising Socrates' method. What do you think about learning by talking with somebody else? What is the difference between Socrates TELLING what justice is and ASKING QUESTIONS to know what it is?

We are trying to learn utilising the same method used by Socrates in the Republic, dialogue. Do you prefer this method of learning to simply listening to the teacher? Explain us what are the reasons which support your answer.

In this unit the students face a complex scenario. The example used to help them to understand the concepts discussed is, in this case, not only taken from their everyday life but it is something that they are living: the students have to criticise the dialogical activity in which they are involved. The results of the students' analyses are unpredictable but, insofar as they are supported by good reasons and they are explained efficaciously, they have to be accepted. I am eager to learn from the students. A good demonstration of the necessity of a change in the project would prove that I have succeeded in my primary goal: the creation of a learning environment that gives children the opportunity to discover who they are, stimulating them to express their rational nature freely. To attain this goal, the material designed for children requires the collaboration of different disciplines: philosophy, education and technology are all necessary in the development of my project. The results obtained with the use of the learning units will give us the chance to discuss childhood knowing what it is. We will learn to value childhood as the precious human resource that it is, instead of considering incomplete the individuals who are telling us who they are, only because they are not adults.

\section{References}

[1] Brown, P. and Lauder, H. (2000). Education, Child Poverty and the Politics of Collective Intelligence. In S.J. Ball (Ed.). (2000). Sociology of Education: Major Themes, Vol. IV (pp. 1753-1779). London: Routledge Falmer

[2] Freire, P. (1970). Pedagogy of the Oppressed. New York: Continuum

[3] Kennedy, D. (2006). Changing Conceptions of the Child from the Renaissance to Post-Modernity: A Philosophy of Childhood. NY Lewinston: The Edwin Mellen Press

[4] Kennedy, D. (2013). Epilogue: Becoming Child, Becoming Other: Childhood as Signifier. In A. Muller (Ed.). (2013). Childhood in the English Renaissance (pp. 145-153). Trier: Wissenschaftlicher Verlag Trier

[5] Matthews, G. B. (2000). The Ring of Gyges. International Journal of Applied Philosophy 14 (1): 3-11

[6] Plato, Republic. 1997. Trans. by Grube, G.M.A, revised by Reeve, C.D.C. In J. M. Cooper (Ed.).(1997). Plato: Complete Works. Indianapolis: Hackett

[7] Saracco, S. (2016). Difference as a Resource for Thinking: An Online Dialogue Showing the Role Played by Difference in Problem Solving and Decision Making. Metaphilosophy. 47 (3): 467-476. 